Studia Anglica Posnaniensia 45/1, 2009

(C) School of English, Adam Mickiewicz University, Poznań, Poland

doi: 10.2478/v10121-009-0008-3

\title{
THE PEDAGOGIC GRAMMARIAN'S DILEMMA: MODALITY AND PERSONALITY IN GRAMMATICAL DESCRIPTION
}

\author{
ROGER BERRY
}

Lingnan University

\begin{abstract}
This paper investigates an issue that I call the "pedagogic grammarian's dilemma": the choice facing writers of pedagogic grammars between being specific about grammar and risking being wrong, or hedging and risking being vague, as formulated by Henry Widdowson (1997). Using two corpora of grammatical description, it examines how a number of exponents of modality are used to hedge and finds firstly that they are far more common than in ordinary text. More importantly there is a link between the use of such modality and the approach to personality chosen in the grammars: hedging is more common when the more friendly $Y O U$ is used to address users than when $W E$ is used; this suggests an interpersonal (as well as epistemic) motivation for the hedging. Overall the response of the grammars studied to the pedagogic grammarian's dilemma is to hedge, in order, it seems, to avoid being prescriptive.
\end{abstract}

\section{Introduction}

In this paper I want to consider an area that is of great interest to me: the metalanguage of pedagogic grammars. By "metalanguage" I understand any kind of language about language (e.g. as defined in Johnson - Johnson 1998), rather than the logician's ideal and distinct system for talking precisely about language. (For a more detailed discussion of the meaning(s) of "metalanguage" see Berry 2005a). I am not so much interested in what such grammars say (the content) as in how they say it (the style), though there is a strong connection between the two.

My reasons for studying this field are two-fold. Firstly, I have been engaged personally, in a modest way, in the writing of pedagogic grammars - having written two books in the Collins Cobuild English guides series (Berry 1993, 1997). While doing this I was aware of being subject to a number of constraints 
that affected what I could say:

- $\quad$ space. Publishers do not have endless resources to accommodate their writers' verbosity; even scholarly grammars (which nowadays approach the 2000 page mark) are subject to constraints on space.

- learner level and maturity. This involves a number of factors which affect the complexity of concepts that can be presented and the kind of language that can be used in description (including terminology). Swan (1994) discusses such criteria, in particular what he calls "conceptual parsimony".

- in-house style. Certain terms and features of style have to be used to conform to that of other publications. In Cobuild publications this meant using terms like "noun group" instead of "noun phrase", and you to address the readers (more on this below).

And all this comes before we start to consider the possibility of incomplete knowledge on the part of the writer. These constraints, along with the tensions and resulting trade-offs they impose, are at the root of what I am calling the "pedagogic grammarian's dilemma". I will return to this central issue in Section 3.

The second reason is that it seems to me that such writing is a valid object of investigation from a linguistic or discourse analytic point of view. However, it does not seem to have attracted the attention of linguists or discourse analysts so far, perhaps because it is too close to the linguist's bone. It seems to be acceptable to study any genre (e.g. academic writing, political speeches, journalism, and so on) so long as it is not in the linguist's backyard. A rare example is Van Leeuwen's (2004) study of three texts written by linguists (including one he cowrote) examining political interviews from a critical discourse perspective.

When it comes to pedagogic metalanguage, there is another dimension which is more applied in nature, namely the way the readers (teachers and learners) react to the text and to its metalingual features. This is an issue that I have considered elsewhere (Berry 2000, 2004), finding that features such as modality and personality do make a difference and do need to be taken into consideration by grammarians:

\footnotetext{
The style used and the metalingual choices made do have an effect on learners; writers need to consider what form (or forms) of personality to adopt and what effect the use of qualification will have on their readers
}

(2004: 15).

\section{The language of grammar}

From my experience of writing about grammar I was already aware of a number of fundamental textual issues that confront the pedagogic gram- 
marian, for example:

- modality, as instantiated by the use of modal verbs, adverbs of frequency and other words. Does the writer say

we use $X$, or

we can use $X$, or

we often use $X \ldots$ ?

The last two options allow writers to pull back from full commitment to the proposition while allowing them to avoid specifying the circumstances. This choice is at the heart of the pedagogic grammarian's dilemma and will be discussed further below.

- personality. This refers to the systemic choice facing writers about whether to place themselves in the text and whether to address the reader. In grammatical terms it involves the choice between personal constructions (and then among personal pronouns) and impersonal constructions (and then between passive and active forms). In pedagogic grammars this gives the following (somewhat simplified) possibilities in English:

$$
\begin{aligned}
& \text { we use X (personal, first person plural) } \\
& \text { you use X (personal, second person) } \\
& X \text { is used (impersonal, passive) } \\
& \text { it is normal to use X (impersonal, active) }
\end{aligned}
$$

A number of variations on these choices exist, particularly for the impersonal active option, and other languages have other possibilities, such as reflexive verbs. The term "personality" (not to be confused of course with another application in Psychology) is taken from Goatly (2000); see also Berry (2004, 2005b) and Coniam (2004). One aim of this paper will be to see how closely it interacts with the previous feature, modality.

- carrier verbs: this is a fairly vague concept, but basically it refers to the verbs that are used to "carry" the descriptive information. Use and say are the basic or neutral carrier verbs; verbs that carry extra information are follow, omit and precede.

Here are some examples from METALANG I (see below) exhibiting all three features:

1) Modals are used in "question tags".

2) You can sometimes use a noun without a determiner.

3) We say a friend of mine/yours/his...

All these three areas play a part (varying in importance) in the current study. There are of course many other features that are typical of pedagogic descrip- 
tion but there is no need or space to go into them here.

4. The pedagogic grammarian's dilemma

In an article enquiring into the nature of metalanguage, Widdowson (1997) points out that since any description of language involves an abstraction, there is bound to be imperfection. As examples of this he cites two texts (1997: 18901892). The first is from Alexander (1993: 288): "The simple past tense describes events, actions or situations which occurred in the past and are now finished. A time reference is usually given or strongly implied". There is a problem with this abstraction, as Widdowson points out:

... the implication is that the use of the simple past in English to describe events, actions and so on is distinctive of this tense. But clearly it is not. The past continuous and past perfect are also used in this way. Nor is it the case that the simple past is used only in reference to past time. It occurs commonly in conditional expressions...

(1997: 1891).

The second text is from Swan (1980: 470-471) (text in parentheses added by Widdowson):

The past tense is the one most often (but not always) used to talk about the past. It
can (but need not) refer to short, quickly finished actions and events, to longer ac-
tions and situations, and to repeated happenings (i.e. it can refer to almost any-
thing).

To paraphrase Widdowson, there seem to be two choices:

- to be specific and risk being wrong, as in Alexander above (though it should be noted that Alexander's second sentence is not specific);

- to be so general as to risk saying nothing as in Swan above, i.e. to "hedge", as Widdowson calls it.

One might want to pass a less harsh verdict on these two attempts, for the task facing pedagogic grammarians is actually more complex than this, involving issues such as space and learner factors as well, as suggested above. Chalker points out that "Learners on the whole want language made easy... They also want prescriptive guidance ...", which may be in conflict with the desire of writers of pedagogic grammars to avoid "falsifying by oversimplifying" (1994: 36).

To recap then, the pedagogic grammarian's dilemma concerns how to reconcile pressures of space (you can't say everything) and learner level (they wouldn't understand it anyway) with accuracy (are you allowed to simplify if it could make what you say prescriptive and/or wrong?) and certainty (can you 
appear uncertain by hedging?).

So the first question in this article is: what do the writers of pedagogic grammars do? Do they use the kind of modality highlighted by Widdowson in Swan or not? This and related questions form the basis of the study that follows below. But first it is necessary to consider the concept of "hedging" that Widdowson has referred to.

\section{Hedging}

The concept of hedging is coming to be a fairly venerable one in Applied Linguistics and the literature on it - in particular concerning Academic Writing (e.g. Hyland 1996, 1998) - is quite extensive. The first thing to note is that Widdowson's interpretation of it is somewhat wider than that generally applied in academic writing, involving root modality (as in the use of can) as well as epistemic modality. The difference can be seen in this example of epistemic modality, where can is not possible:

4) You may be right. (= it is possible that you are right)

(For more on this distinction see Quirk et al. 1985: 223).

However, if we compare Quirk et al.'s definition of modality in general:

At its most general, modality may be defined as the manner in which the meaning
of a clause is qualified so as to reflect the speaker's judgement of the likelihood of
the proposition it expresses being true

(1985: 219)

with Hyland's definition of hedging, which

... refers to any linguistic means used to indicate either a) a lack of complete commitment to the truth value of an accompanying proposition, or b) a desire not to express that commitment categorically

(1998: 1)

we can see that the two concepts are very similar. And the meaning of modal verbs is notoriously difficult to pin down, especially in the area of possibility/permission (see, for example, Biber et al. 1999) and elsewhere (Hyland 1998: 247).

Returning to pedagogic grammar, in a sentence such as

5) All past tense modals can be used in this way.

the use of can implies that the writer is pulling back from a full commitment to 
the underlying proposition, namely the use of past tense modals in a certain way, i.e. is hedging. We can paraphrase it here by saying "It is possible for all past tense modals to be used in this way", adding, as might Widdowson, "but they don't have to be". Can here functions as a kind of "get-out" clause; writers can use it to cover themselves against counter-examples. In this sense, the root modality of pedagogic grammar serves the same function as the epistemic modality of academic writing. If can was removed from the original there would be no such lack of commitment:

6) All past tense modals are used in this way.

This seems to be a stronger statement. (Interestingly, may here would have the same effect as can). It would seem useful, then, to extend the concept of hedging to root modality, as Widdowson does, when studying pedagogic grammar.

One central concept of hedging in academic discourse is that it is not only motivated by a lack of certainty about propositions (Hyland 1998). Hedging occurs even when writers are completely sure of their facts; they hedge in order not to force their arguments down the throats of their readers (who are likely to be their academic peers), in order to allow some space for disagreement, in order to conform to the expectations of their academic community.

In other words we can distinguish two broad functions of hedging (corresponding to the two factors in Hyland's definition):

- the epistemic (which is to do with the writer's attitude towards the facts)

- the interpersonal (which is to do with the writer's relationship with the reader)

Below we will see how this might be applied to grammatical description. An initial working hypothesis would be that pedagogic grammars have no need for the interpersonal function since there is an unequal power relationship between the participants. Unlike in academic and scientific discourse, the writer has no need to mollify the reader; the reader's ratification of claims is not required (Hyland 1996). Myers (1992) reached a similar conclusion when comparing textbooks and research papers, in that the latter involves communication between insiders, whereas the former, as with grammatical description, involves interaction between insider (expert) and outsider (novice/learner/non-native speaker).

Thus we might distinguish two interpersonal motivations:

- a desire not to force facts onto the reader (which may be relevant in pedagogic grammar in order to avoid prescriptivism)

- a desire to conform to the norms of the community (which should not be relevant, in that there is no community as such) 
Below we will see how this might actually be applied.

5. The corpora

To assist in this investigation, I set up two electronic corpora of text from grammars of English:

METALANG I - which contains matching samples of 11 grammars, 10 of which were pedagogic in nature, and one scholarly (Quirk et al.'s Comprehensive grammar of the English language); the total size was approximately 85,000 words. A full list of the grammars is appended. ${ }^{1}$

METALANG II - which consists of 3 pedagogic grammars in their entirety: English grammar in use by Raymond Murphy ( ${ }^{\text {nd }}$ edition 1994), henceforth referred to as MURPHY, Practical English usage by Michael Swan $\left(2^{\text {nd }}\right.$ edition 1995), henceforth SWAN, and the Collins Cobuild English grammar (1990), henceforth COBUILD. Together they amounted to 245,000 words.

MURPHY is a practice grammar in that short introductions to formal topics are followed by related exercises; it aims at the middle and upper-intermediate level. It is intended to be used selectively and flexibly (page ix) in principle with the help of a teacher. SWAN is a reference grammar aimed at intermediate and advanced students and teachers (page xi); it contains short entries on alphabetically-arranged topics that users may consult in isolation. COBUILD is the longest of the three; it has been written "primarily for students of advanced levels" (1990: v), though teachers, examiners, syllabus planners and materials writers are also mentioned. It has a functional-semantic organisation and aims to be systematic. As such it may be termed a "language-system" oriented grammar as opposed SWAN, which is more learner-problem oriented. Thus the three books, though all have a pedagogic rationale, approach grammar in very different ways and aim at different audiences. (For more on classifying grammars see Leech 1994.) ${ }^{2}$

As it was the metalanguage of grammatical description that was under study, the texts were shorn of tables and examples and, where included, exercises. The nature of examples would in particular be worthy of study, but this is not the place for it.

METALANG I was designed to offer a more representative look at the genre, whereas METALANG II was designed to allow intensive study of different individual works and comparison of their styles. And while both are small in the context of current multi-million-word general corpora (and even compared to other more specific corpora) it will be seen that they are large enough for

1 In order to increase comparability, the samples were all taken from comparable sections, i.e. those dealing with the same grammatical topic (e.g. modal verbs).

2 All three grammars have since had further editions. However, the style in each remains the same. 
their purpose.

Some brief general findings from METALANG I may be appropriate here. What stood out immediately was the repetitive, even formulaic nature of the texts. Strings of words occurred regularly. Here are some common two and three-word strings with the keyword CAN (a word that will figure below) in METALANG I:

$\begin{array}{lrlr}\text { can also } & 118 & \text { can also be } & 59 \\ \text { can be } & 272 & \text { can be used } & 109 \\ \text { you can } & 261 & \text { you can use } & 58 \\ \text { we can } & 88 & \text { we can use } & 41\end{array}$

Together these eight phrases constitute more than $2 \%$ of the running text of the corpus (after discounting duplication). It would seem that writers operate with a set of basic building blocks when describing English grammar (which of course is not to deny the possibility of creativity or elegant variation).

\section{Selection of items}

In order to investigate the extent of hedging in general in pedagogic grammars a number of lexical items were selected for investigation; there was no attempt to be exhaustive. The items were chosen on the basis of the author's experience of their frequency in grammatical description. They were taken from two areas highlighted by Widdowson in Swan's text above:

- modal verbs: $C A N, M A Y$

- adverbs of indefinite frequency (OFTEN, SOMETIMES) and usuality (USUALLY, GENERALLY, NORMALLY, termed "usual occurrence" in Quirk et al. 1985: 543) ${ }^{3}$

Here are some examples, all taken from SWAN:

7) We can use the future perfect to say something...

8) In some structures we may put the prepositional object...

9) "Indeed" is often used after an adjective or adverb...

10) Sometimes we leave out "if I were you" and just use "I should"...

11) We usually put the marker "to" before the infinitive...

12) We generally use "in" and "on" to talk about the position of things...

3 A number of similar other adverbs have a similar function (though not the same meaning) but are less frequent: COMMONLY, CHIEFLY, MAINLY, OCCASIONALLY, RARELY. Other grammatical areas that are common in academic writing were not included, such as modal adjectives (e.g. "possible") and lexical verbs ("it seems that", "it is believed that"). 
13) Passive infinitives are normally made by putting "not" before the infinitive.

There is no claim that the seven items are equivalent in meaning. As regards the modals, both $C A N$ and $M A Y$ in grammatical description generally refer to the idea of possibility, thought the latter is regarded as more formal. As regards the adverbs there are subtle differences between GENERALLY, NORMALLY and USUALLY, but the fact that they occupy the same functional ground is shown by their inability to combine - you cannot say "sometimes they are generally used". However, there is no such limitation on the modal verbs combining with the adverbs so clearly there is a difference between them. The adverbs weaken the basic proposition in terms of indefinite frequency or usuality while the modals do it terms of unspecified possibility. But both allow for exceptions to the basic rule - exceptions which are not specified. Thus in

we can use...

we sometimes use...

SOMETIMES functions, like CAN, as a "get-out clause" for writers, as was mentioned above.

Indeed, the similarity between CAN and SOMETIMES has been noted (Swan 2005; Huddlestone - Pullum 2002: 183); Carter and McCarthy (2005: 642) also mention its use to refer to "what is usually the case" as in

14) These animals can be dangerous.

which can be glossed as 'these animals are sometimes dangerous'. However, the two can still "combine harmoniously", as Huddleston and Pullum put it (2002: $183)$, as in

15) These animals can sometimes be dangerous.

Such cases of "double hedging", where both adverb and modal are used, are common in grammatical description ("can often be used", "we may sometimes say") and will provide some interesting evidence later on in this study.

\section{Results from METALANG I}

Table 1 below shows the frequency of the seven selected items in METALANG I. The figures shown have been cleansed of obvious distractors such as homonyms ("May is the fifth month") and citation forms ("we use can ..."), but beyond this there was no attempt to select tokens according to their specific function in grammatical description. For one thing this would have invalidated the comparison with other corpora. The aim here is principally to show the extent of such modality in grammars.

As can be seen, $C A N$, at 769 occurrences, was the most frequent of the seven 
items and was three times more frequent than any other (column 2); together the seven made up almost $2 \%$ of the running text of METALANG I. For the sake of comparison the same seven items were searched for in the Cobuild Direct Corpus - a general corpus (of approximately 57 million words) based on a number of written and spoken genres. The advantage of using Cobuild Direct (henceforth $\mathrm{CD}$ ) is that its component sub-corpora can be searched independently. Thus rather than having a comparison of the corpus in general, it was possible to compare each word with its use in each sub-corpus. Columns 4 and 5 show the highest and lowest frequency (per million words) for each word in any CD sub-corpus. The final column then compares this to its frequency in METALANG I.

Table 1. The frequency of the seven items in METALANG I compared to Cobuild Direct. (All frequencies are per one million words)

\begin{tabular}{|c|c|c|c|c|c|}
\hline \multirow[t]{2}{*}{ Item } & \multicolumn{2}{|c|}{ METALANG I } & \multicolumn{2}{|c|}{ Cobuild Direct corpora } & \multirow{2}{*}{$\begin{array}{c}\text { Ratio range between } \\
\text { Cobuild Direct and } \\
\text { METALANG }\end{array}$} \\
\hline & total & $\begin{array}{l}\text { frequency per } \\
\text { million words }\end{array}$ & $\begin{array}{l}\text { highest } \\
\text { frequency }\end{array}$ & $\begin{array}{c}\text { lowest } \\
\text { frequency }\end{array}$ & \\
\hline CAN & 769 & 8992.0 & 3494.7 & 1157.1 & $7.77 / 2.57: 1$ \\
\hline MAY & 234 & 2736.2 & 1484.5 & 341.4 & $8.02 / 1.84: 1$ \\
\hline USUALLY & 173 & 2022.9 & 227.9 & 46.0 & 43.97/8.87:1 \\
\hline NORMALLY & 98 & 1145.9 & 157.2 & 31.0 & 39.96/7.29:1 \\
\hline GENERALLY & 47 & 549.6 & 102.9 & 14.1 & 38.98/5.34:1 \\
\hline OFTEN & 183 & 2139.9 & 542.2 & 146.6 & 14.60/3.95:1 \\
\hline SOMETIMES & 171 & 1999.5 & 310.4 & 55.6 & 35.96/6.44:1 \\
\hline
\end{tabular}

As can be seen, the seven items were far more common in METALANG I. Both modals occurred from approximately two up to eight times more frequently in METALANG I than they did in the CD sub-corpora. But it with the adverbs (with the possible exception of OFTEN) that the difference was most pronounced; USUALLY, for example, occurred between 9 and 44 times more frequently. That they would be more frequent in relative terms than the modals could be expected - the modal verbs have other meanings beyond possibility, whereas the adverbs are restricted to it, hence the dramatic increase in their use in grammars. All of which suggests that hedging is relatively very common in grammatical description. Of the two options posed by Widdowson it seems that the second - to generalize and avoid being wrong - is common.

As was mentioned above, METALANG I consisted of 10 pedagogic grammars and one scholarly: Quirk et al.'s Comprehensive grammar. It was thought useful to make a comparison between them to see if there is a difference in the use of modality between scholarly and pedagogic grammars this was possible since Quirk et 
al. contributed a sizeable portion of METALANG I (over a quarter).

It was hypothesized that two factors might be working against each other in Quirk et al. One is the already-mentioned interpersonal motivation in more academic writing not to force facts onto readers. This, however, would be in conflict with the obvious position of Quirk and his co-authors as supreme experts in the field; they are not writing a journal article aimed at their peers. And a grammar that calls itself "comprehensive" is clearly claiming a position of authority.

Table 2 shows the results of this comparison. By comparing the figures for frequency per million words we can see that of the seven words, five are relatively less frequent in Quirk et al.: CAN, USUALLY, NORMALLY, OFTEN and SOMETIMES. And overall the proportion of the seven words in the text is less: $1.4 \%$ versus $2.2 \%$ in the rest of METALANG I. However, there are two items which are more frequent: GENERALLY (twice as frequent) and MAY (almost three times). This may be to do with the more formal nature of the latter ("we may say" vs "we can say") and the more academic tone conveyed by the former. And we should not discount the possibility of there being other exponents of hedging found in the more academic Quirk et al. but not feasible in pedagogic grammars. Overall the conclusion must be that scholarly grammars also hedge for interpersonal reasons, but in different ways; the desire to avoid appearing prescriptive may be the rationale for it.

Table 2. Differences between Quirk et al. and the rest of METALANG I

\begin{tabular}{|c|c|c|c|c|}
\hline \multirow[t]{2}{*}{$\begin{array}{l}\text { Item } \\
\text { CAN }\end{array}$} & \multicolumn{2}{|c|}{$\begin{array}{l}\text { METALANG I without Quirk et al. } \\
(61,857) \\
\text { total frequency } \\
\text { per million }\end{array}$} & \multicolumn{2}{|c|}{$\begin{array}{l}\text { Quirk et al. } \\
\qquad(23,663) \\
\text { total frequency } \\
\text { per million } \\
\end{array}$} \\
\hline & 669 & 10,815 & 100 & 4,226 \\
\hline MAY & 115 & 1,859 & 119 & 5,029 \\
\hline USUALLY & 160 & 2,587 & 13 & 549 \\
\hline NORMALLY & 76 & 1,228 & 22 & 930 \\
\hline GENERALLY & 26 & 420 & 21 & 888 \\
\hline OFTEN & 159 & 2,570 & 24 & 1,014 \\
\hline SOMETIMES & 146 & 2,359 & 25 & 1,057 \\
\hline Total & 1,351 & 21,841 & 324 & 13,694 \\
\hline
\end{tabular}

\section{Findings from METALANG II: Modality}

The results from METALANG I are a rather blunt instrument; there is no guarantee that the incidence of the seven items is related to grammatical description in the narrow sense, which is the major function of interest here. The results merely show that this kind of modality is far more frequent in grammars than in 
English generally. Indeed, this finding was reduplicated for the three grammars studied intensively in METALANG II; once cleansed, there were 1539 tokens of CAN in SWAN (1.2\% of the total), 1647 in COBUILD (1.6\%), and 265 in MURPHY (1.3\%). This suggests that such modality is common in pedagogic grammars, regardless of their audience.

However, for the principal focus in METALANG II a specific context was applied in order to ensure that grammatical description in a narrow sense was under study. The search was restricted to the use of modality with the carrier verbs USE and SAY; in the case of USE both passive and active forms were sought ("we can use"/"can be used"); for $S A Y$ the passive not an option. Cases where $S A Y$ was clearly referring to speech as opposed to writing (i.e. where it could not be considered a neutral carrier verb) were not included.

For the purpose of simplicity at this stage of the research the modals were cut from two to one, the far more frequent $C A N$. Table 3 shows the results. As before, distractors were removed, in particular the noun uses of use.

Table 3. Incidence of $C A N$ and main adverbs with carrier verbs

\begin{tabular}{l|c|c|c|c|c|c}
\hline & \multicolumn{2}{|c|}{ SWAN } & \multicolumn{2}{c|}{ COBUILD } & \multicolumn{2}{c}{ MURPHY } \\
\hline & USE(D) & SAY & USE(D) & SAY & USE(D) & SAY \\
\hline a) carrier verbs: raw total & 2754 & 282 & 2718 & 500 & 575 & 313 \\
b) with CAN & 661 & 18 & 924 & 115 & 137 & 86 \\
c) with USUALLY & 77 & 11 & 82 & 6 & 6 & 11 \\
d) with OFTEN & 255 & 4 & 101 & 1 & 42 & 1 \\
e) with SOMETIMES & 79 & 2 & 103 & 2 & 18 & - \\
f) with GENERALLY & 62 & 2 & 3 & - & 2 & - \\
g) with NORMALLY & 154 & - & 37 & 3 & 37 & - \\
h) total (b) - (g) & 1288 & 37 & 1250 & 127 & 242 & 98 \\
i) percentage (h) in (a) & $47 \%$ & $13 \%$ & $46 \%$ & $25 \%$ & $42 \%$ & $31 \%$ \\
\hline
\end{tabular}

As can be seen, of the two verbs $S A Y$ is much less frequent; only once, in MURPHY in the context of USUALLY, does it exceed the frequency of $U S E(D)$ (though it approaches it in the context of $C A N$ in the same book). Indeed, this seems to be part of a broader pattern of low frequencies for $\operatorname{USE}(D)$ in the context of USUALLY; USUALLY is less frequent overall (162 tokens) than OFTEN (398) and SOMETIMES (200), which was not the case with the general picture in METALANG I and II. Perhaps this is because "we/you usually use" sounds tautological. Another reason why $\operatorname{USE}(D)$ is relatively less frequent in MURPHY compared to $S A Y$ is that the passive is rare (presumably because the author considers it more difficult to decode than the active).

Again, though, the overall finding is that modality is common even with this more precise definition of grammatical description. A large proportion of the 
tokens of USE and SAY occur in the context of one of these items, suggesting that one of the main functions of these carrier verbs is to act as a hook for hedging (and of course there may be more hedging using items not considered here which would have raised the percentages). It is also interesting to note how similar the three percentages for hedging with $\operatorname{USE}(D)$ were in the three books, as noted in Table $3(47 \%, 46 \%$ and $42 \%)$, and how high they were compared to those for $S A Y$. It seems that the former is the standard hook for hedging.

Likewise, one of the main functions of these forms of modality, particularly the adverbs, is to hedge in these precise contexts. For example, in MURPHY 37 of the 45 tokens of NORMALLY occurred with $\operatorname{USE}(D)$.

The results also add to the evidence for the formulaic nature of such writing; the instances of "can use" and "can be used" formed roughly half of all tokens of $C A N$ in each of the three grammars - 142 out of 265 for MURPHY (56\%), 662 out of 1411 for SWAN (47\%), and 920 out of 1639 for COBUILD (56\%).

\section{Findings from METALANG 2: Personality}

METALANG II also offers a useful basis for investigating the interpersonal motivation for hedging (as discussed above) via the concept of personality, and the investigation of whether there is a correlation between personality and modality forms the focus of this last part of the paper. In other words, the aim is to see whether the interpersonal motivation for hedging also applies to grammatical description.

For the purpose of this paper the study of personality was restricted to the choice of personal pronouns, namely $W E$ and $Y O U$, and initially a comparison was made only between SWAN and COBUILD, since, although they target similar audiences, they differ significantly in their approach to personality: the former predominantly uses the traditional $W E$ while the latter adopts the same style introduced in other Cobuild publications (notably the Cobuild dictionaries) with heavy emphasis on the use of YOU to address the reader, in contrast to traditional lexicographese. It is a style which has been called "youser-friendly" (Berry 2000). It should be noted, though, that both books also make copious use of impersonal structures such as the passive. ${ }^{4}$ MURPHY, as will be seen later, uses both pronouns.

The assumption here is that $Y O U$ can be taken as more of an indicator of the interpersonal function than $W E$ can. There are problems with youser-friendly metalanguage (as pointed out in Berry 2000), but these concern reader reaction rather than writer intention. And some authors may consider that $W E$ is also

4 It would be interesting to investigate why grammars switch between personal and impersonal structures, and indeed between $Y O U$ and $W E$ sometimes, but this is not the place. 
intended to convey a friendly tone (compared to, say, passives) but its use is often unclear as to an exclusive or inclusive interpretation (for more on this distinction see Quirk et al. 1985: 341); clearly the former is less friendly. Several writers, e.g. Wales (1996), Flowerdew (1997), have noted the indeterminacy of $W E$ and how this can be exploited for rhetorical purposes by politicians. It may be that grammarians use $W E$ for similar reasons.

Here is an example of WE from SWAN (1995: 247):

16) We use "special" tenses with "if" when we are talking about unreal situations...

It is not immediately obvious whether this should be taken as exclusive or inclusive. The writer's intention may have been to involve readers but it could equally be interpreted by non-native learners as referring to a community of expert speakers of which they are not part. ${ }^{5}$ And it may depend on other factors. Berry (2005a) has noted how an exclusive interpretation is more likely if $W E$ is juxtaposed with $Y O U$, as sometimes occurs in pedagogic grammars. But whether $W E$ is interpreted here as exclusive or inclusive, distant or friendly, it still involves the writer, the authority, as opposed to YOU. One can therefore expect that with the latter there would be more hedging. Indeed, the very use of $Y O U$ in these circumstances necessitates a revision of the initial working hypothesis (in Section 4) that hedging in pedagogic grammars would be inappropriate because of the distance between writer and readers. Clearly if a writer is getting close to his or her readers by using $Y O U$, an interpersonal motivation for hedging is also feasible; he or she may wish to avoid sounding prescriptive and authoritative.

Table 4 shows the comparison between the two books, starting with the overall incidence of "use" and "used" as verbs and then refining it to see how likely $C A N$ is to occur in the context PRONOUN USE. Because of its low frequency in the above part of this study, $S A Y$ has been omitted.

Table 4. Incidence of pronouns with CAN and USE

\begin{tabular}{l|c|c}
\hline & SWAN & COBUILD \\
\hline Total USE(D) (verb) & 2754 & 2718 \\
Total USE (verb) & 831 & 1055 \\
as infinitive & 56 & 69 \\
with other subjects & 44 & 22 \\
WE USE & 731 & 4 \\
YOU USE & - & 960 \\
CAN USE & $176(\mathrm{WE})$ & 413 (YOU) \\
\hline
\end{tabular}

5 There are clear cases of exclusivity in cases functioning as metadiscourse: "we described this in the previous chapter". 
$\%$ CAN with WE/YOU $24 \%$ $43 \%$

As can be seen, the incidence of $\operatorname{USE}(D)$, apart from being high, is remarkably similar in the two books (2754 compared to 2718), but when the passive constructions are omitted (and they are in the majority in both books) in order to focus on personal pronoun use with the verb, there were rather more instances of USE (as an active verb) in COBUILD (1051) than in SWAN (831); this difference ( 965 to 731 ) was still maintained when its uses as infinitive and with other subjects (most commonly "people") were stripped out.

The table shows that while SWAN is entirely consistent in its choice between the two pronouns - only using $W E$ - COBUILD allowed four cases of $W E$ to "slip through"; nevertheless $Y O U$ greatly predominates in COBUILD. These instances of "we use" and "you use" were then further investigated to see how often $C A N$ occurred between them. The final row shows the cases where the pronoun (WE in SWAN and YOU in COBUILD) was followed by $C A N$ in the context of $U S E$ as a percentage of the overall cases. As can be seen, $C A N$ was far likely to be used with YOU USE in COBUILD (43\%) than with WE USE in SWAN (24\%)

Now this difference is not conclusive; it can be put down to a difference in style between the authors of the grammars. Perhaps the writer(s) of COBUILD simply like to limit their commitment by using $C A N$. But it is surely not a coincidence that the book which opts deliberately for a more "personal" approach to its audience via the use of $Y O U$ is more likely to hedge its statements by the use of CAN.

For more specific evidence of the interpersonal function of hedging we turn to cases of double-hedging, as described above; that is, where $C A N$ was used in conjunction with one of the adverbs. Table 5 correlates this against pronoun use in all three books.

Table 5. Adverbs correlated with pronouns and $C A N$ according to grammar

\begin{tabular}{l|c|c|c|c|c|c|c|c|c|c|c|c}
\hline & \multicolumn{4}{|c|}{ SWAN } & \multicolumn{3}{c|}{ MURPHY } & \multicolumn{3}{|c}{ COBUILD } \\
\hline & we & we & you & you & we & we & you & you & we & we & you & you \\
& - & can & - & can & - & can & - & $\begin{array}{c}\text { can } \\
\text { can }\end{array}$ & - & - & can \\
& use & - & use & - & use & - & use & - & use & - & use & - \\
& & use & & use & & use & & use & & use & & use \\
\hline USUALLY & 54 & - & - & - & 1 & - & - & 2 & - & - & 30 & - \\
OFTEN & 82 & 3 & - & - & 33 & - & - & 3 & - & - & 6 & 6 \\
SOMETIMES & 7 & 4 & - & - & 12 & - & - & 3 & - & - & 3 & 11 \\
GENERALLY & 13 & 2 & - & - & 2 & - & - & - & - & - & 1 & - \\
NORMALLY & 22 & - & - & - & 29 & - & - & 1 & - & - & 17 & - \\
\hline Total & 178 & 9 & - & - & 77 & - & - & 9 & - & - & 57 & 17 \\
\hline
\end{tabular}


The table repeats what is already known about SWAN and COBUILD, i.e. that the former does not use YOU and the latter eschews $W E$ - the tokens for SWAN are in the left two columns while those for COBUILD are in the two right-hand columns. More significantly, those with $C A N$ in SWAN are less frequent than those without it (i.e. "we can often use" is much less frequent than "we often use" - as might be expected). In COBUILD, double-hedging is more frequent than in SWAN (17 vs 57 compared with 9 vs 160 in SWAN), particularly in the case of SOMETIMES, but single hedging with the adverb still predominates.

The most interesting finding comes from the middle four columns representing the results for MURPHY. As can be seen, this grammar uses both pronouns (though $W E$ is more common). The important point is that it uses them in different contexts; with an adverb $W E$ only occurs without $C A N$, while $Y O U$ only occurs with it. There are no cases either of $W E+C A N+A D V+U S E$ or of YOU $+A D V+U S E$ (without $C A N$ ). In other words, the two pronouns are in a kind of complimentary distribution in this specific context, and it is not impossible that the choice of pronoun is being determined by the amount of hedging; doublehedging encourages the use of $Y O U$, while single does not.

Overall the results show a strong tendency to use hedging with $Y O U$, much stronger than to use it with $W E$. However, clearly much more research is needed to support these findings.

\section{Conclusions}

A number of tentative conclusions can be reached from the above discussion:

- there is a lot of hedging in pedagogic grammars. $C A N$ is particularly common and is used frequently in phrases of a formulaic nature such "can be used"

- scholarly grammars hedge as well but in different ways

- the amount of modality used to hedge in different pedagogic grammars is related to not only to the epistemic rationale for hedging but also to the interpersonal; the more friendly the approach to personality the greater the use of hedging

- carrier verbs may be used as hooks to hang modality on, especially USE

- double-hedging (“...can sometimes...”) is more likely with YOU than with $W E$

Though hedging is obviously common in pedagogic grammars, it does not mean that this is the writers' only response to the pedagogic grammarian's dilemma. There are many places in the grammars studied where unqualified statements are made. And it is possible that other grammars not studied here, in 
particular those aimed at beginners, would go exclusively for the other option, i.e. simplicity and certainty at the risk of being wrong. But we should not be surprised that hedging is so common in pedagogic grammars. Even in cases where the writers are familiar with the facts and have no need to hedge, there is a tendency to do so, in line with the interpersonal motivation for hedging. In other words, they do not want to appear prescriptive.

In general we should be sympathetic towards writers faced by the pedagogic grammarian's dilemma. They hedge not only because they want to avoid being wrong - or because they do not have the space - or because their learners can't take in everything (or even because they don't know the facts); they do it also in order to give their readers some space. It is almost as though they are addressing not learners of the language but teachers and possibly other grammarians. In this sense, as part of a community, it would be inappropriate to force their ideas on their colleagues, just as is the case in academic writing.

Whether such a hedging style is appropriate in pedagogic grammar is of course another matter. And indeed, as Widdowson identified, there are certainly grammars out there (which were not included in METALANG I or II) where the alternative, prescriptive approach is taken. But nowadays the trend certainly seems to be towards hedging in response to the pedagogic grammarian's dilemma.

Acknowledgement

METALANG I and II were compiled with the help of grants from Lingnan University, Hong Kong.

\title{
REFERENCES
}

\author{
Alexander, L. G. \\ 1993 Longman advanced grammar. London: Longman. \\ Andrews, Stephen \\ 1999 "Why do L2 teachers need to 'know about language'? Teacher \\ metalinguistic awareness and input for learning", Language and Education 13/3: 161- \\ 177. \\ Berry, Roger \\ 1993 Articles. London: HarperCollins. \\ 1997 Determiners and quantifiers. London: HarperCollins. \\ 2000 “'Youser-friendly' metalanguage: What effect does it have on learners of English?", \\ International Review of Applied Linguistics 38: 195-211. \\ 2004 "Awareness of metalanguage", Language Awareness 13/1: 1-16. \\ 2005a "Making the most of metalanguage", Language Awareness 14/1: 3-20. \\ 2005 b "Who do they think 'we' is? Learners' awareness of personality in pedagogic gram-
}


mars", Language Awareness 14/2 and 3: 84-96.

Biber, Douglas - Stig Johansson - Geoffrey Leech - Susan Conrad - Edward Finegan

1999 The Longman grammar of spoken and written English. Harlow: Longman.

Bygate, Martin - Alan Tonkyn - Eddie Williams (eds.)

1994 Grammar and the language teacher. Hemel Hempstead: Prentice Hall International.

Carter, Ronald - Michael McCarthy

2005 Cambridge grammar of English. Cambridge: Cambridge University Press.

Chalker, Sylvia

1994 "Pedagogical grammar; principles and problems", in: Martin Bygate - Alan Tonkyn -

Eddie Williams (eds.), 31-44.

Collins Cobuild English grammar

1990 London: Collins.

Coniam, David

2004 "Concordancing yourself: A personal exploration of academic writing", Language Awareness 13/1: 49-55.

Flowerdew, John

1997 "The discourse of colonial withdrawal: A case study in the creation of mythic discourse", Discourse in Society 8: 453-477.

Goatly, Andrew

2000 Critical reading and writing. London: Routledge.

Hickey, Raymond - Stanisław Puppel (eds.)

1997 Language history and linguistic modelling. Vol. II: Linguistic modelling. Berlin: Walter de Gruyter.

Huddleston, Rodney - Geoffrey Pullum

2002 The Cambridge grammar of the English language. Cambridge: Cambridge University Press.

Hyland, Ken

1996 "Writing without conviction? Hedging in scientific research articles", Applied Linguistics 17: 433-454.

1998 Hedging in scientific research articles. Amsterdam - Philadelphia: Benjamins.

Jaworski, Adam - Nikolas Coupland - Dariusz Galasiński (eds.)

2004 Metalanguage: Social and ideological perspectives. Berlin: Mouton de Gruyter.

Johnson, Keith - Helen Johnson

1998 Encyclopedic dictionary of applied linguistics. Oxford: Blackwell.

Leech, Geoffrey

1994 “Students' grammar - teachers' grammar - learners' grammar", in: Martin Bygate Alan Tonkyn - Eddie Williams (eds.), 17-30.

van Leeuwen, Theo

2004 "Metalanguage in social life", in: Adam Jaworski - Nikolas Coupland - Dariusz Galasiński (eds.), 107-130.

Murphy, Raymond

1994 English grammar in use. Cambridge: Cambridge University Press.

Myers, Greg

1992 "Textbooks and the sociology of scientific knowledge", English for Specific Purposes 11: 3-17.

Quirk, Randolph - Sidney Greenbaum - Geoffrey Leech - Jan Svartvik

1985 A comprehensive grammar of the English language. Harlow: Longman. 
Swan, Michael

1994 "Design criteria for pedagogic language rules", in: Martin Bygate - Alan Tonkyn Eddie Williams (eds.), 45-55.

1995 Practical English usage. Oxford: Oxford University Press.

Wales, Katie

1996 Personal pronouns in Present-day English. Cambridge: Cambridge University Press.

Widdowson, Henry

1997 "Metalanguage and interlanguage", in: Raymond Hickey - Stanisław Puppel (eds.), 1887-1899.

\section{APPENDIX}

Books used in METALANG I

Beaumont, Digby - Colin Granger

1989 The Heinemann English grammar. Oxford: Heinemann.

Chalker, Sylvia

1990 English grammar word by word. Walton-on-Thames: Nelson.

Greenbaum, Sidney

1996 The Oxford English grammar. Oxford: Oxford University Press.

Greenbaum, Sidney - Randolph Quirk

1990 A students' grammar of the English language. Harlow: Longman. Collins Cobuild English grammar

1990 London: Collins.

Leech, Geoffrey - Jan Svartvik

1994 A Communicative grammar of English. Harlow: Longman.

Master, Peter

1996 Systems in English grammar. Englewood Cliffs, NJ: Prentice Hall Regents.

Quirk, Randolph - Sidney Greenbaum - Geoffrey Leech - Jan Svartvik

1985 A comprehensive grammar of the English language. Harlow: Longman.

Murphy, Raymond

1994 English grammar in use. Cambridge: Cambridge University Press.

Swan, Michael

1995 Practical English usage. Oxford: Oxford University Press.

Thomson, A. J. - A. V. Martinet

1986 A practical English grammar. Oxford: Oxford University Press. 